\title{
A Switched-Capacitor Interleaved Bidirectional Converter with Wide Voltage-Gain Range for Super Capacitors in EVs
}

Yun Zhang, Senior Member, IEEE, Wei Zhang, Fei Gao, Member, IEEE, Shenghan Gao, and Daniel J. Rogers, Senior Member, IEEE

\begin{abstract}
A switched-capacitor interleaved bidirectional (SCIB) dc-dc converter that combines a three-phase interleaved structure with switched-capacitor cells is proposed. The converter features a wide-voltage-gain range, low current ripple on the low voltage side, low voltage stresses across power switches, an absolute common ground between input and output, and can be easily extended into a topology family. The operating principle and power switch voltage and current stresses are analyzed in detail. An $800 \mathrm{~W}$ prototype with a wide voltage gain range $\left(U_{\text {high }}=400 \mathrm{~V}, U_{\text {low }}=30-100 \mathrm{~V}\right)$ is described, demonstrating a maximum efficiency of $95.8 \%$ in the step-up mode and $95.9 \%$ in the step-down mode.
\end{abstract}

Index Terms-Bidirectional dc-dc converter, electric vehicles, super capacitor, three-phase interleaved, wide voltage gain range.

\section{INTRODUCTION}

Hybrid energy source electric vehicles(EVs), whose power system consists of high energy density batteries and high power density super capacitors, as shown in Fig.1, are an import part of the drive toward lower-carbon and lower-pollution transportation systems [1]-[5]. The battery bidirectional dc-dc converter (BDC) maintains a stable dc bus voltage, and the motor is driven by the power from the dc bus through the inverter. The working conditions of EVs produce high-frequency dynamic power demands during acceleration and regenerative breaking. To reduce stress on the battery and improve overall system efficiency, these high peak power demands can be serviced by a super capacitor. In order to make full use of the power capacity of the super capacitor and to exploit its high power density characteristic, it is necessary to dynamically match the wide voltage range of the super capacitor with the constant dc bus voltage. Accordingly, the bidirectional power interface between the super capacitor and the dc bus requires a wide voltage gain range.

Bidirectional dc-dc converters can be divided into two categories: isolated and non-isolated converters. Isolated converters can achieve a high voltage gain by using a transformer with a large turns ratio, but usually cannot provide a high voltage gain range (i.e. ratio between maximum and minimum output voltages) with high efficiency. The bridge converters (e.g. dual active bridge) are the most common type of isolated converters, where the voltage stresses experienced by the power switches are equal to the output voltage [6].

Manuscript received Feb. 25, 2019; accepted Jun. 1, 2019. This work was supported in part by the National Natural Science Foundation of China under Grants 51577130 and 51207104, and in part by the Research Program of Application Foundation and Advanced Technology of Tianjin China under Grant 15JCQNJC03900.

Y. Zhang, W. Zhang and S. Gao are with the School of Electrical and Information Engineering, Tianjin University, Nankai, Tianjin, China (e-mail: zhangy@tju.edu.cn; duanyidelei@163.com; 18811757258@163.com).

F. Gao and D. J. Rogers are with the Department of Engineering Science, University of Oxford, UK. (email: fei.gao@eng.ox.ac.uk; dan.rogers@eng.ox.ac.uk).

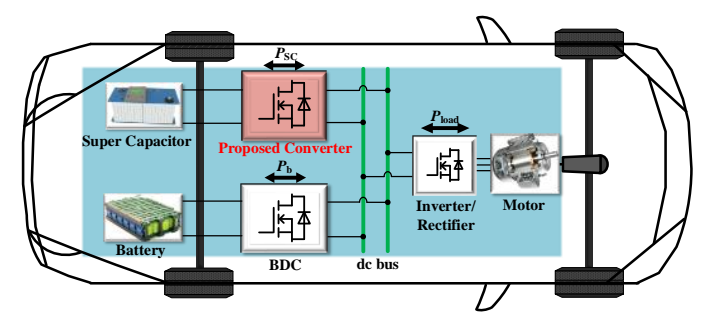

Fig.1. Powertrain of hybrid energy sources EVs.

Non-isolated bidirectional dc-dc converters include the conventional two-level Buck/Boost converter, Cuk/Sepic/Zeta converters, multi-level converters, coupled-inductor converters, switched-capacitor and switched-inductor converters, etc. The conventional bidirectional Buck/Boost converter can realize bidirectional power flows between the low voltage side (LVS) and the high voltage side (HVS), but the converter is subject to extreme duty cycles when a wide voltage gain range is required. In addition, the voltage stresses across power switches are as high as the voltage on the HVS. Although the $\mathrm{Cuk} / \mathrm{Sepic} / Z$ ta converters can achieve a wide voltage gain range without operating under extreme duty cycle conditions, the power conversion efficiency is limited by their cascaded structures [7], [8]. Multi-level dc-dc converters greatly reduce the voltage stresses across power switches by employing more power switches, however, additional hardware as well as more complex control strategies are required [9]-[11]. Coupled-inductor dc-dc converters can achieve a high voltage gain by adjusting the turns ratio of the coupled inductors, but the order of the converter will be higher, which demands a more complicated control system [12]. In some cases, transformer leakage inductance results in voltage spikes across the power switches, requiring additional components to absorb the leakage inductance energy [13]. Coupled inductors can also impose complex requirements on the design of the magnetic elements [14]. Switched-inductor bidirectional dc-dc converters can achieve a wide voltage gain range without extreme duty cycles. However, the use of multiple inductors limits the power density of the converters [15], [16].

Switched-capacitor dc-dc converters are simple in structure and relatively easy to extend; in these converters, the capacitors transfer energy through different paths during charging and discharging processes to obtain a high voltage gain [17], [18]. The voltage gain can be increased by cascading basic switched-capacitor cells in [17], but the range of the voltage gain is limited: it can only be an integer multiple and has no dependency on the duty cycle. Two output capacitors are connected in series to increase the voltage gain range in [18]. However, the input and output do not share a common ground and the required output capacitance is relatively large. Coupled inductors are charged in parallel and discharged in series in [19] to improve the voltage gain of the converter, however, the leakage inductance can cause voltage spikes across power switches if 
snubber circuits are not included. In addition, this type of converter does not have a common ground between the input and output. In [20], a structure in which a switched-inductor and a switched-capacitor are connected in series is proposed to increase the voltage gain. However, the series structure of the inductor and capacitor can generate oscillating current, and a large inductance is required to reduce the current ripple on the LVS. A hybrid bidirectional dc-dc converter serving as an interface between two dc voltage buses in dc microgrids is proposed in [21]. Although the switched-capacitor cell gives the advantage of a high voltage gain, the power switch between the input and output grounds generates a high-frequency potential difference. In addition, the voltage stresses across the power switches remain high which limits its applications.

In order to tackle some of the shortcomings of previously proposed circuits, this paper proposes a three-phase interleaved bidirectional dc-dc converter suitable for use as the super capacitor interface in hybrid energy sources EVs. This circuit has a wide voltage gain range and so can provide the dynamic matching between the super capacitor voltage and the constant dc bus voltage. Additionally, a three-phase interleaved structure based on switched-capacitor cells greatly reduces the current ripple on the LVS, as well as reducing the voltage stresses across the power switches. The SCIB converter is easy to extend and has an absolute common ground between the input and output. Thus, the main advantages of the SCIB converter include wide range of voltage gain, reduced current ripple and voltage stress of the power switches and good topology scalability.

The structure of the paper is organized as follows: In Section II, the topology of the SCIB converter is introduced and its operating principle is illustrated in detail. Section III analyzes the steady-state characteristics of the converter and performs a comparative analysis with competing converters, and shows an extended topology. Experimental results are presented in Sections IV and finally Section V draws the conclusion.

\section{OPERATING PRINCIPLE AND PARAMETERS DESIGN}

\section{A. Operating Principle}

The configuration of the SCIB converter is depicted in Fig.2, which consists of a basic Buck/Boost network $\left(L_{1} 、 Q_{1}\right.$ 、 $Q_{4}$ and $\left.C_{\mathrm{h} 1}\right)$ and two extended Buck/Boost networks $\left(L_{2} 、 Q_{2}\right.$ 、 $C_{1} 、 Q_{6} 、 C_{\mathrm{h} 2}$ and $\left.L_{3} 、 Q_{3} 、 C_{2} 、 Q_{8} 、 C_{\mathrm{h} 3}\right)$, power switches $Q_{5}$ 、
$Q_{7}$ and energy storage/filter capacitor $C_{\text {low }}$ on the LVS. The SCIB converter can operate either in the step-up or step-down mode, enabling bidirectional power flow between the HVS and LVS.

To simplify the analysis, it is assumed that all the components are ideal: the on-state resistance $R_{\mathrm{DS}}$ of the power switches and equivalent series resistance (ESR) of the inductors and capacitors are ignored, and voltages across capacitors are constant.

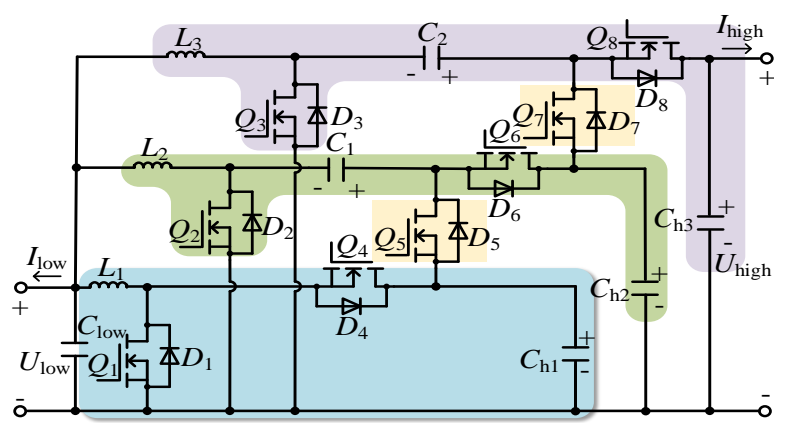

Fig.2 Configuration of the SCIB converter.

When the SCIB converter operates in the step-up mode, $Q_{1}-Q_{3}$ are the main power switches, and body diodes $D_{4}-D_{8}$ of $Q_{4}-Q_{8}$ are the freewheeling diodes. The duty cycles of the gate signals $S_{1}-S_{3}$ are taken as $d_{1}=d_{2}=d_{3}=d_{\text {Boost }}$, and are phase shifted by $120^{\circ}$ in turn. When the SCIB converter operates in the step-down mode, $Q_{4}-Q_{8}$ are the main power switches, and body diodes $D_{1}-D_{3}$ of $Q_{1}-Q_{3}$ are the freewheeling diodes. The duty cycles of the gate signal $S_{4}-S_{8}$ are taken as

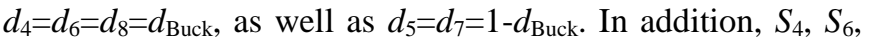
and $S_{8}$ are phase shifted by $120^{\circ}$ in turn. $S_{5}, S_{7}$ are complementary to $S_{6}, S_{8}$ respectively. The characteristic waveforms of the SCIB converter operating in continuous conduction mode (CCM) are shown in Fig.3 and Fig.5. It can be seen from Fig.3 and Fig.5 that the duty cycle ranges include three cases: $0<d_{\text {Boost }}\left(d_{\text {Buck }}\right) \leq 1 / 3,1 / 3<d_{\text {Boost }}\left(d_{\text {Buck }}\right) \leq 2 / 3$, and $2 / 3<d_{\text {Boost }}\left(d_{\text {Buck }}\right)<1$. Only the case of $1 / 3<d_{\text {Boost }}\left(d_{\text {Buck }}\right) \leqslant$ $2 / 3$ will be discussed further, since the others operate in a very similar fashion. The corresponding current paths in the case of $1 / 3<d_{\text {Boost }} \leqslant 2 / 3$ and $1 / 3<d_{\text {Buck }} \leq 2 / 3$ are illustrated in Fig. 4 and Fig.6, respectively. The steady-state values of all the eight states are listed in TABLE I and the steady-state characteristics are analyzed in Section III (which are valid for all three duty cycle ranges).

TABLE I STEAdy-State ANAlysis Of The SCIB CONVERTER

\begin{tabular}{|c|c|c|c|c|c|c|c|c|c|}
\hline \multicolumn{5}{|c|}{ Step-up mode } & \multicolumn{5}{|c|}{ Step-down mode } \\
\hline State & $S_{1} S_{2} S_{3}$ & $U_{\mathrm{L} 1}$ & $U_{\mathrm{L} 2}$ & $U_{\mathrm{L} 3}$ & State & $S_{4} S_{5} S_{6} S_{7} S_{8}$ & $U_{\mathrm{L} 1}$ & $U_{\mathrm{L} 2}$ & $U_{\mathrm{L} 3}$ \\
\hline 1 & 101 & $U_{\text {low }}$ & $U_{\text {low }}+U_{\mathrm{Cl} 1}-U_{\mathrm{Ch} 2}$ & $U_{\text {low }}$ & 1 & 11001 & $U_{\text {low }}-U_{\mathrm{Ch} 1}$ & $U_{\text {low }}$ & $U_{\text {low }}+U_{\mathrm{C} 2}-U_{\text {high }}$ \\
\hline 2 & 100 & $U_{\text {low }}$ & $U_{\text {low }}+U_{\mathrm{Cl} 1}-U_{\mathrm{Ch} 2}$ & $U_{\text {low }}+U_{\mathrm{C} 2}-U_{\text {high }}$ & 2 & 11010 & $U_{\text {low }}-U_{\mathrm{Ch} 1}$ & $U_{\text {low }}$ & $U_{\text {low }}$ \\
\hline 3 & 110 & $U_{\text {low }}$ & $U_{\text {low }}$ & $U_{\text {low }}+U_{\mathrm{C} 2}-U_{\text {high }}$ & 3 & 10110 & $U_{\text {low }}-U_{\mathrm{Ch} 1}$ & $U_{\text {low }}+U_{\mathrm{C} 1}-U_{\mathrm{Ch} 2}$ & $U_{\text {low }}$ \\
\hline 4 & 010 & $U_{\text {low }}-U_{\mathrm{Ch} 1}$ & $U_{\text {low }}$ & $U_{\text {low }}+U_{\mathrm{C} 2}-U_{\text {high }}$ & 4 & 00110 & $U_{\text {low }}$ & $U_{\mathrm{low}}+U_{\mathrm{Cl} 1}-U_{\mathrm{Ch} 2}$ & $U_{\text {low }}$ \\
\hline 5 & 011 & $U_{\mathrm{low}}-U_{\mathrm{Ch} 1}$ & $U_{\text {low }}$ & $U_{\text {low }}$ & 5 & 00101 & $U_{\text {low }}$ & $U_{\text {low }}+U_{\mathrm{Cl} 1}-U_{\mathrm{Ch} 2}$ & $U_{\text {low }}+U_{\mathrm{C} 2}-U_{\text {high }}$ \\
\hline 6 & 001 & $U_{\text {low }}-U_{\mathrm{Ch} 1}$ & $U_{\text {low }}+U_{\mathrm{Cl} 1}-U_{\mathrm{Ch} 2}$ & $U_{\text {low }}$ & 6 & 01001 & $U_{\text {low }}$ & $U_{\text {low }}$ & $U_{\text {low }}+U_{\mathrm{C}^{2}}-U_{\text {high }}$ \\
\hline 7 & 000 & $U_{\text {low }}-U_{\mathrm{Ch} 1}$ & $U_{\text {low }}+U_{\mathrm{Cl} 1}-U_{\mathrm{Ch} 2}$ & $U_{\text {low }}+U_{\mathrm{C} 2}-U_{\text {high }}$ & 7 & 01010 & $U_{\text {low }}$ & $U_{\text {low }}$ & $U_{\text {low }}$ \\
\hline 8 & 111 & $U_{\text {low }}$ & $U_{\text {low }}$ & $U_{\text {low }}$ & 8 & 10101 & $U_{\text {low }}-U_{\mathrm{Ch} 1}$ & $U_{\text {low }}+U_{\mathrm{C} 1}-U_{\mathrm{Ch} 2}$ & $U_{\text {low }}+U_{\mathrm{C} 2}-U_{\text {high }}$ \\
\hline
\end{tabular}




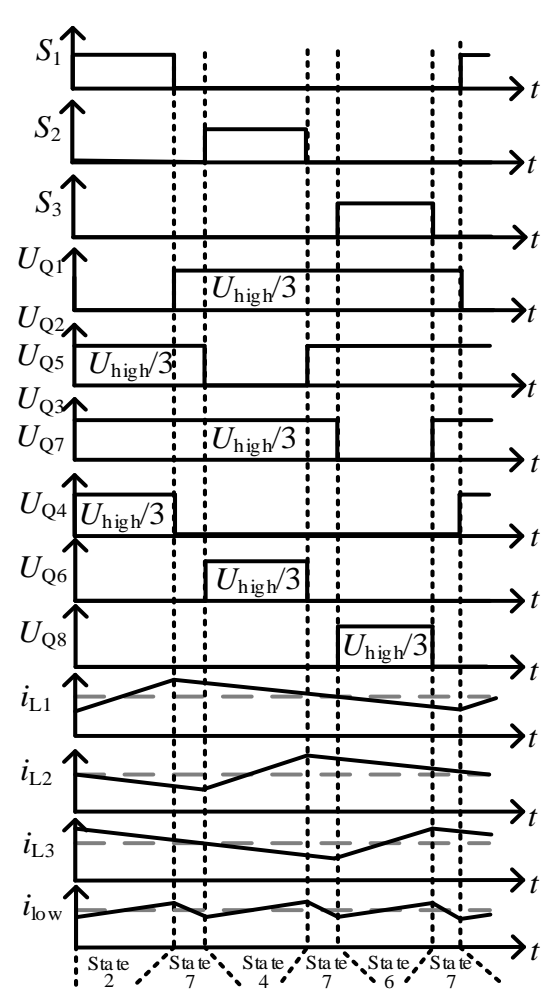

(a)

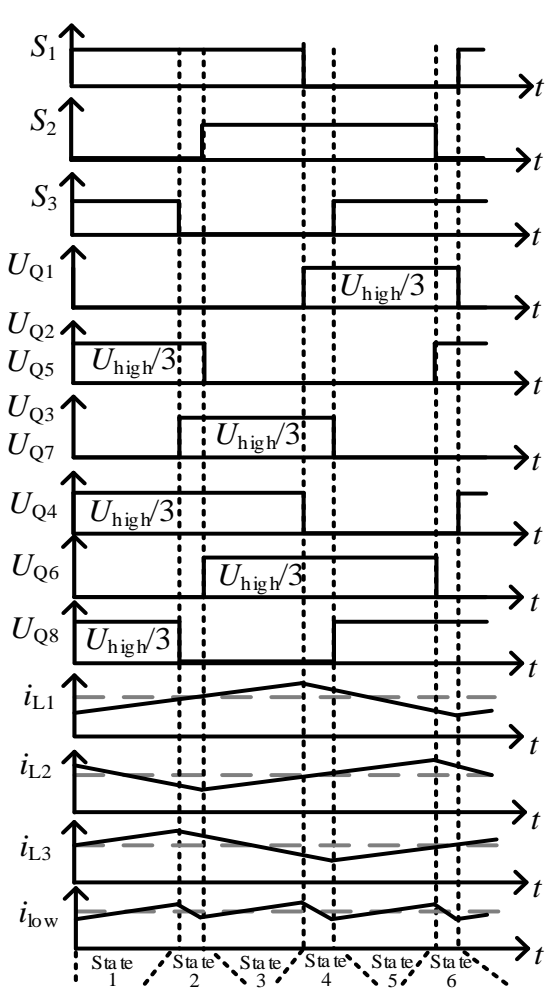

(b)
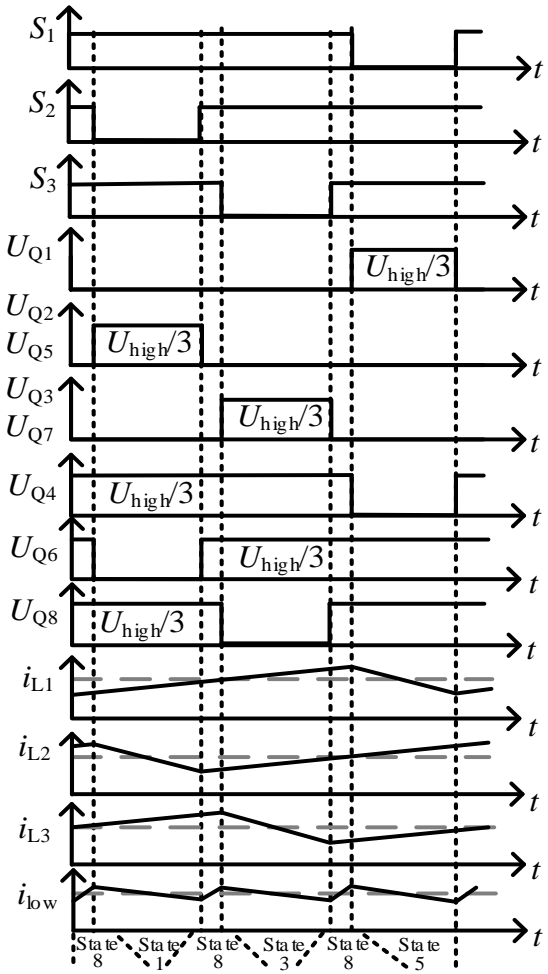

(c)

Fig.3 Characteristic waveforms in the step-up mode. (a) $0<d_{\text {Boost }} \leq 1 / 3$. (b) $1 / 3<d_{\text {Boost }} \leq 2 / 3$. (c) $2 / 3<d_{\text {Boost }}<1$.

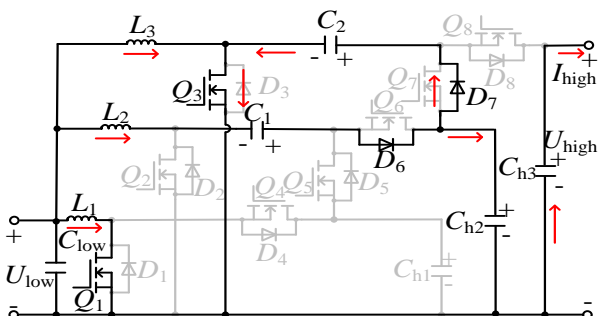

(a)

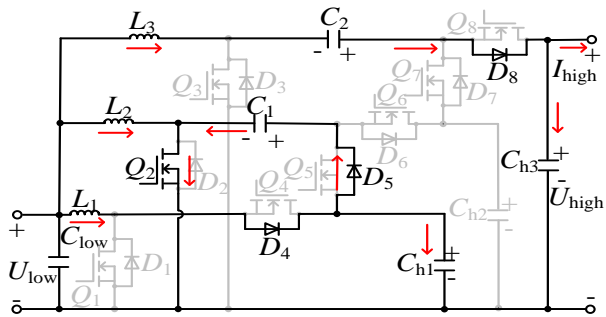

(d)

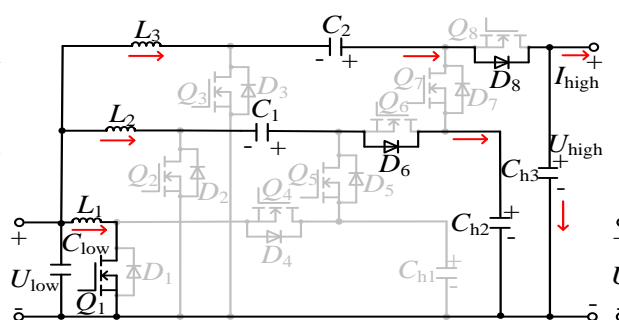

(b)

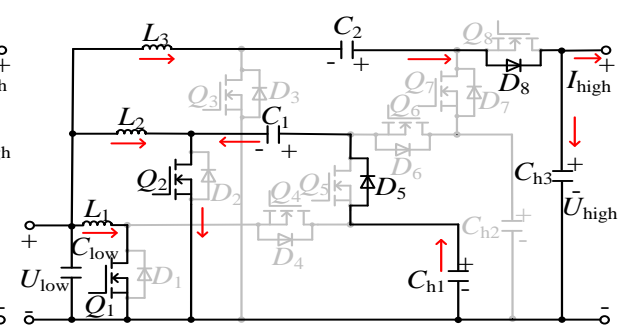

(c)

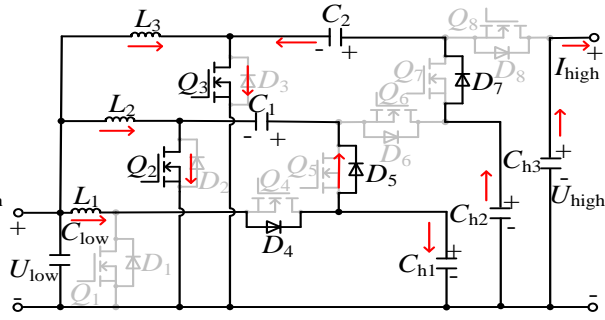

(e)

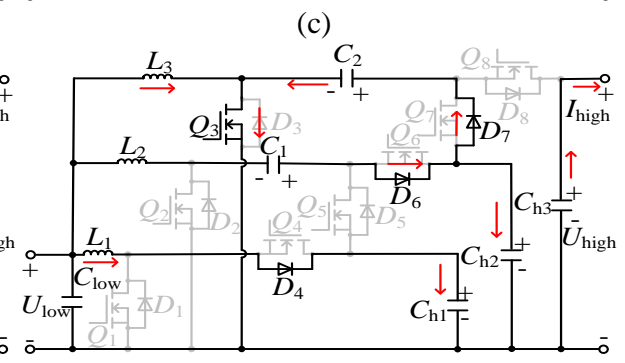

(f)

Fig.4 Current-flow paths in the step-up mode $\left(1 / 3<d_{\text {Boost }} \leqslant 2 / 3\right)$.(a)State 1. (b)State 2. (c)State 3. (d)State 4. (e)State 5. (f)State 6.

\section{B. Design of Inductors and Capacitors}

The inductance of the inductors $L_{1}-L_{3}$ can be obtained as:

$$
L_{1}=L_{2}=L_{3}=\frac{U_{\text {low }} d_{\text {Boost }}}{f_{\mathrm{s}} \Delta I_{\mathrm{L}}}
$$

Note however that the three-phase interleaving reduces the current ripple further on the LVS as follows:

$$
\Delta I_{\text {low }}= \begin{cases}d_{\text {Boost }}\left(\frac{1}{3}-d_{\text {Boost }}\right) \frac{U_{\text {high }}}{f_{\mathrm{s}} L} & 0<d_{\text {Boost }}<\frac{1}{3} \\ \left(d_{\text {Boost }}-\frac{1}{3}\right)\left(\frac{2}{3}-d_{\text {Boost }}\right) \frac{U_{\text {high }}}{f_{\mathrm{s}} L} & \frac{1}{3} \leq d_{\text {Boost }}<\frac{2}{3} \\ \left(d_{\text {Boost }}-\frac{2}{3}\right)\left(1-d_{\text {Boost }}\right) \frac{U_{\text {high }}}{f_{\mathrm{s}} L} & \frac{2}{3} \leq d_{\text {Boost }}<1\end{cases}
$$

The maximum increase of the charge stored in capacitor $C_{\text {low }}$ in step-down mode for every switching cycle $1 / f_{\mathrm{S}}$ is

$$
\Delta Q=\frac{\Delta I_{\text {low }}}{8 f_{\mathrm{s}}}
$$

Therefore, the minimum value of capacitor $C_{\text {low }}$ can be achieved as

$$
C_{\text {low }}=\frac{\Delta I_{\text {low }}}{8 f_{\mathrm{s}} \Delta U_{\text {low }}}
$$

The capacitances of capacitors $C_{1}$ and $C_{2}$ can be calculated as well

$$
\begin{gathered}
C_{1} \geq \frac{\left(1-d_{\text {boost }}\right) I_{\mathrm{L} 2}}{f_{\mathrm{S}} \Delta U_{\mathrm{C} 1}} \\
C_{2} \geq \frac{\left(1-d_{\text {boost }}\right) I_{\mathrm{L} 3}}{f_{\mathrm{S}} \Delta U_{\mathrm{C} 2}}
\end{gathered}
$$

In order to eliminate the impact of asymmetry, $C_{\mathrm{h} 1}$ and $C_{\mathrm{h} 2}$ are equal to $C_{1}$ and $C_{2}$ respectively. Similarly, the capacitance 


$$
C_{\mathrm{h} 3} \geq \frac{\left(1-d_{\text {boost }}\right) I_{\text {high }}}{f_{\mathrm{S}} \Delta U_{\text {high }}}
$$

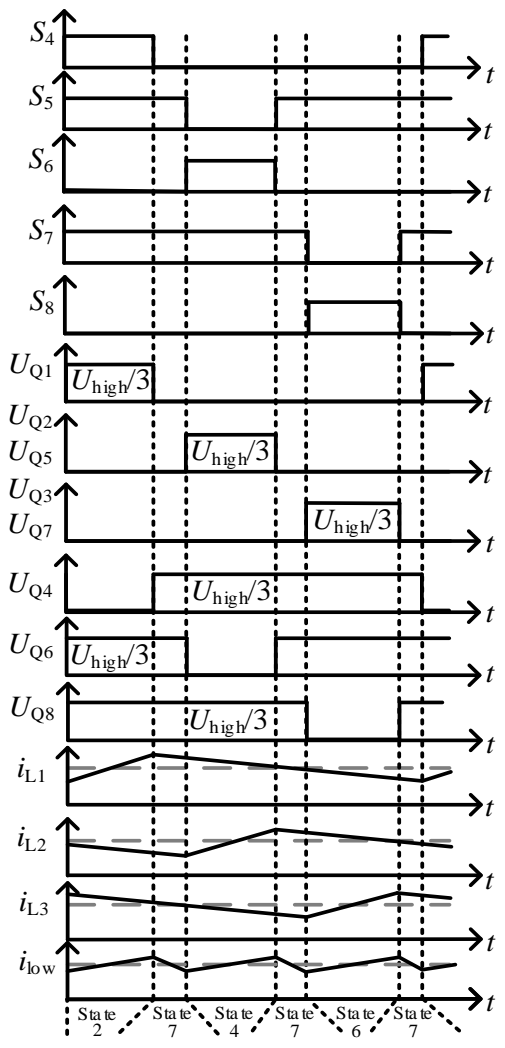

(a)

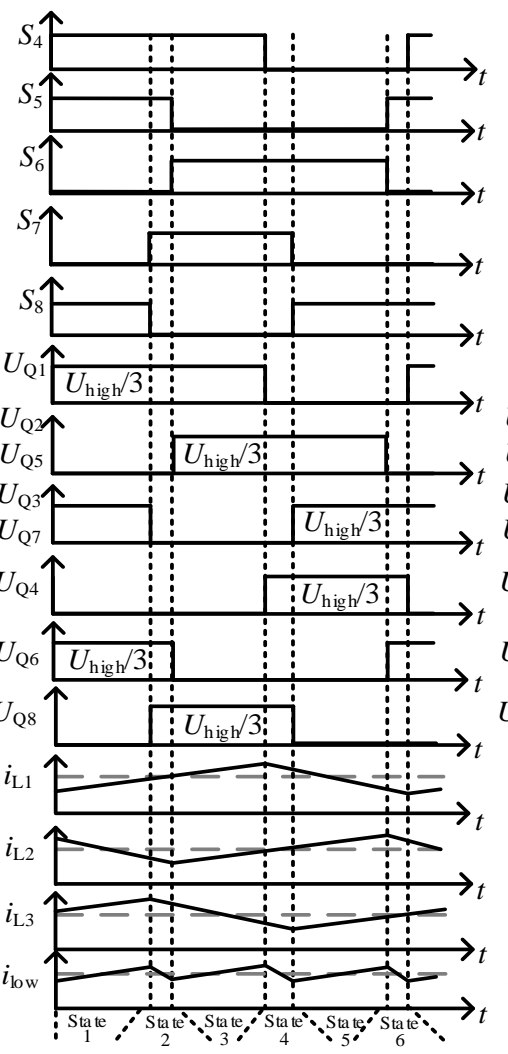

(b)

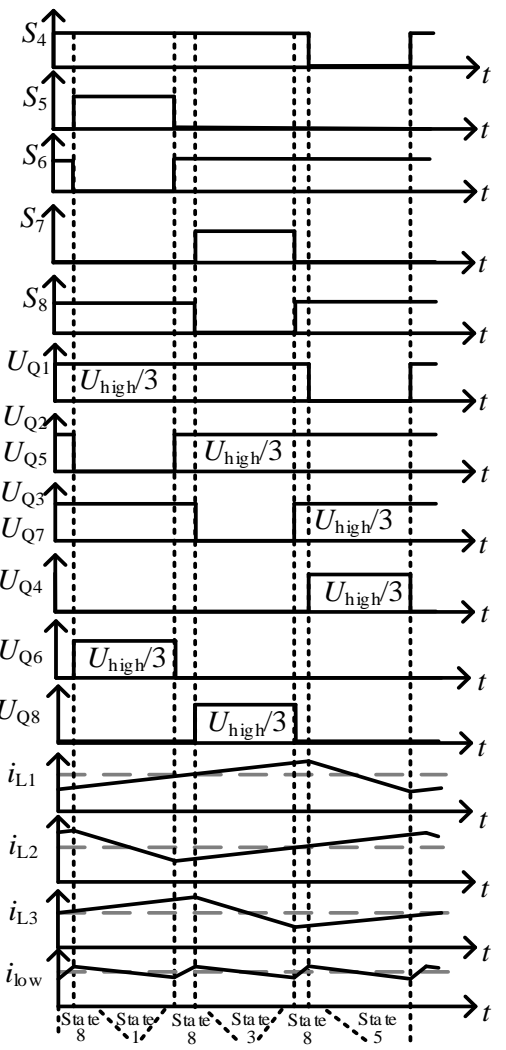

(c)

Fig.5 Characteristic waveforms in the step-down mode. (a) $0<d_{\text {Buck }} \leqslant 1 / 3$. (b) $1 / 3<d_{\text {Buck }} \leqslant 2 / 3$. (c) $2 / 3<d_{\text {Buck }}<1$.

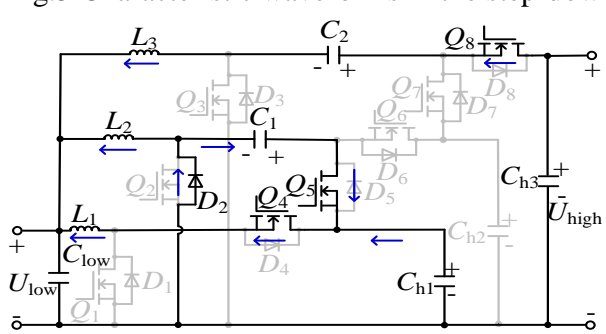

(a)

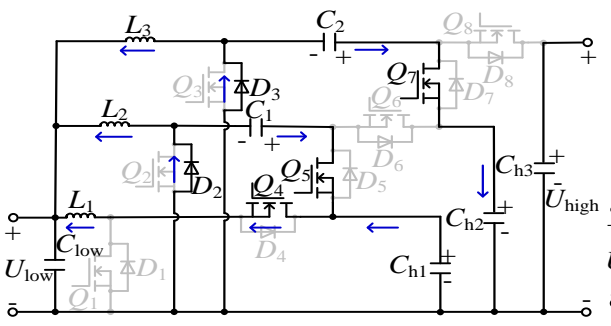

(b)

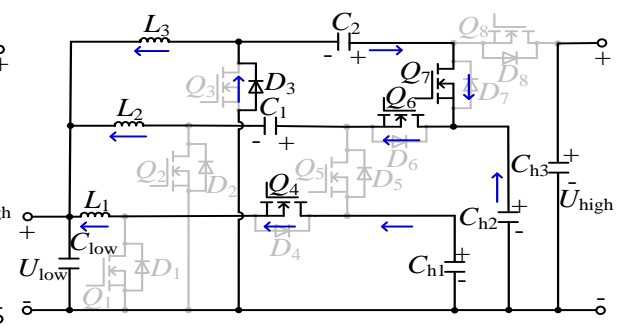

(c)

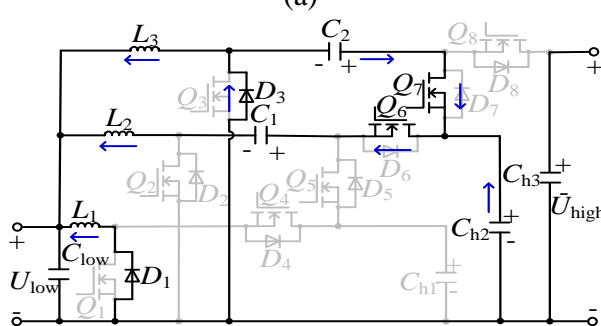

(d)

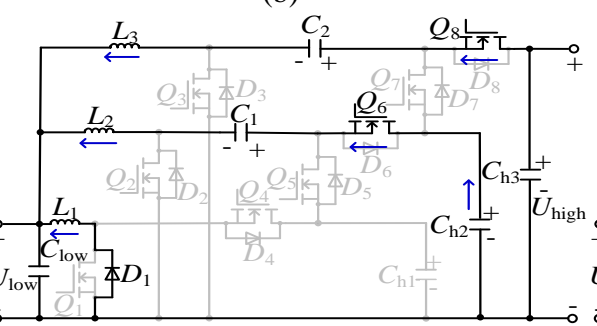

(e)

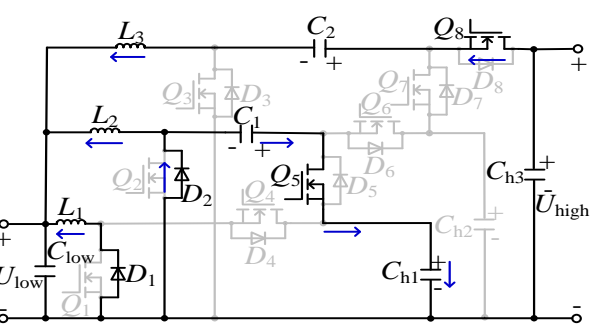

(f)

Fig.6 Current-flow paths in the step-down mode $\left(1 / 3<d_{\text {Buck }} \leqslant 2 / 3\right)$. (a)State 1. (b)State 2. (c)State 3. (d)State 4. (e)State 5. (f)State 6.

\section{Design of Current Controller}

The SCIB converter utilizes double-loop control in the off-system experiments. In this case, Fig.7 shows the control arrangement for step-up/down modes, where $U_{\mathrm{g} 1}-U_{\mathrm{g} 3}$ are the gate signals of power switches $Q_{1}-Q_{3}$, and $U_{\mathrm{g} 4}-U_{\mathrm{g} 8}$ are the gate signals of power switches $Q_{4}-Q_{8}$. Owing to the step-up mode and step-down mode can refer to each other, only the current controller in step-down mode is analyzed further, the outer voltage loop is similar. It is assumed that the power switches, inductors, and capacitors are analyzed under ideal conditions. The load resistance is $R_{\text {Buck }}$, and $u_{\text {high }}(t), i_{\text {low }}(t)$ and $d_{\text {Buck }}$ are the input variable, the output variable and the control variable, respectively. $i_{\mathrm{L} 1}(t), i_{\mathrm{L} 2}(t), i_{\mathrm{L} 3}(t), u_{\mathrm{C} 1}(t), u_{\mathrm{C} 2}(t)$, $u_{\mathrm{Ch} 1}(t), u_{\mathrm{Ch} 2}(t)$, and $u_{\text {Clow }}(t)$ are the state variables. In order to avoid the invalid state variables, the equivalent series resistors $R_{\mathrm{Ch} 1}, R_{\mathrm{Ch} 2}$ for $C_{\mathrm{h} 1}$ and $C_{\mathrm{h} 2}$ are introduced

Applying the state space averaging method to all the states over one switching period, the small signal model of the SCIB converter in the step-down mode can be derived as (8): 


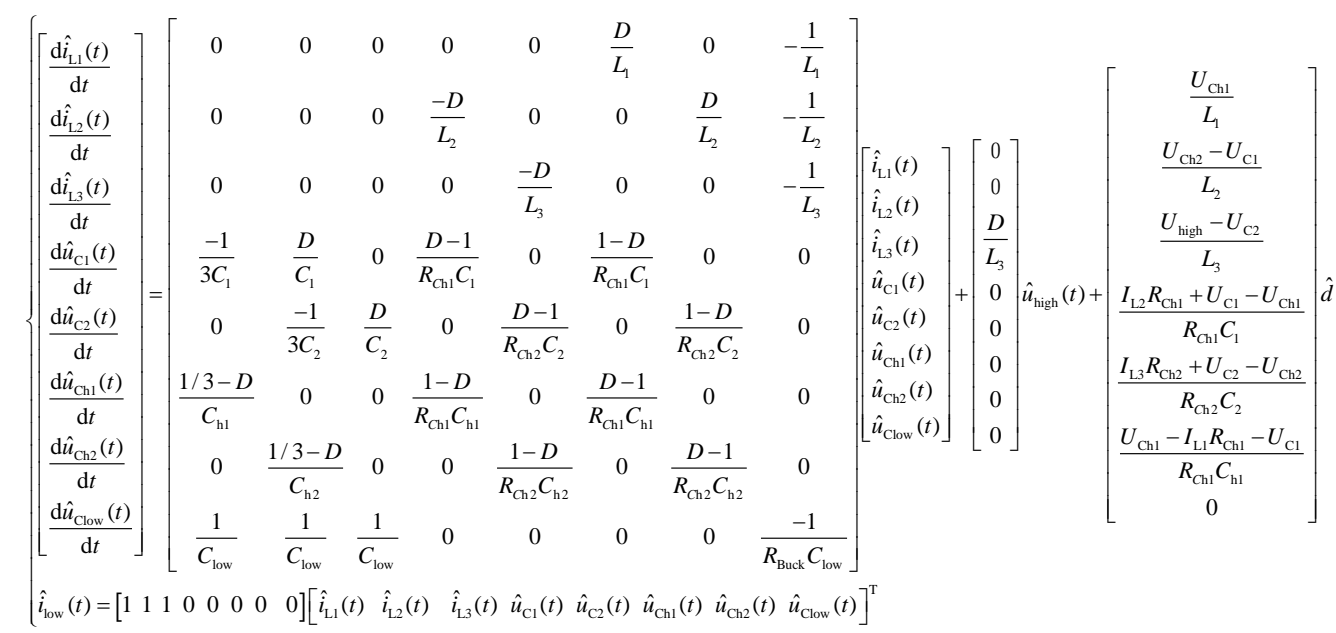

By substituting the parameters in TABLE III into (8), the transfer function in the step-down mode can be obtained.

$$
\begin{aligned}
& G_{\text {id }}(s)=\left.\frac{\hat{i}_{\text {Low }}(s)}{\hat{d}(s)}\right|_{\hat{u}_{\text {nigh }}(s)=0}= \\
& \frac{2.5 \times 10^{16} s^{7}+7.1 \times 10^{21} s^{6}+5.0 \times 10^{26} s^{5}+6.1 \times 10^{29} s^{4}+1.5 \times 10^{33} s^{3}+1.8 \times 10^{36} s^{2}+8.4 \times 10^{38} s+9.8 \times 10^{41}}{2.2 \times 10^{10} s^{8}+6.2 \times 10^{15} s^{7}+4.4 \times 10^{20} s^{6}+7.3 \times 10^{23} s^{5}+1.5 \times 10^{28} s^{4}+2.1 \times 10^{30} s^{3}+4.2 \times 10^{34} s^{2}+1.2 \times 10^{36} s+2.3 \times 10^{40}}
\end{aligned}
$$

The current-loop control scheme for the SCIB converter is depicted in Fig.8, where $G_{\text {id }}(s)$ is the control to output current transfer function of the converter, $G_{\mathrm{m}}(s)$ is the transfer function of pulse-width modulator, $H(s)$ is the feedback transfer function and $G_{\mathrm{c}}(s)$ is the current controller transfer function (i.e. a PI controller) shown in (10). Thus the current controller can be designed for the SCIB converter to achieve a better stability performance.

$$
\begin{aligned}
& G_{\text {Buck }}(s)=G_{\mathrm{c}}(s) G_{\mathrm{m}}(s) G_{\text {id }}(s) H(s)= \\
& \frac{2.5 \times 10^{13} s^{8}+7.4 \times 10^{18} s^{7}+5.8 \times 10^{23} s^{6}+5.7 \times 10^{27} s^{5}+7.6 \times 10^{30} s^{4}+1.7 \times 10^{34} s^{3}+1.8 \times 10^{37} s^{2}+9.4 \times 10^{39} s+9.8 \times 10^{42}}{2.2 \times 10^{10} s^{9}+6.2 \times 10^{15} s^{8}+4.4 \times 10^{20} s^{7}+7.3 \times 10^{23} s^{6}+1.5 \times 10^{28} s^{5}+2.1 \times 10^{30} s^{4}+4.2 \times 10^{34} s^{3}+1.2 \times 10^{36} s^{2}+2.3 \times 10^{40} s}
\end{aligned}
$$

The bode diagram of $G_{\text {Buck }}(\mathrm{s})$ is shown in Fig.9. It can be seen that the magnitude margin and phase margin are both greater than 0 , which demonstrates that the closed-loop system with PI current controller can operate stably in the step-down mode.

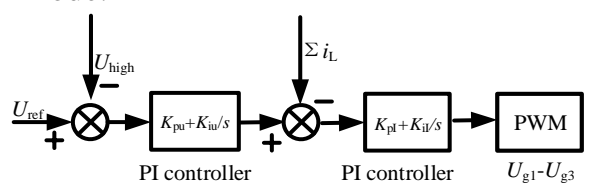

(a)

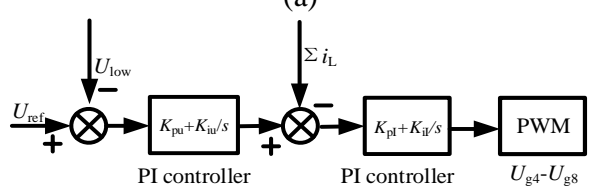

(b)

Fig.7 Double-loop control diagram. (a)Step-up mode. (b)Step-down mode.

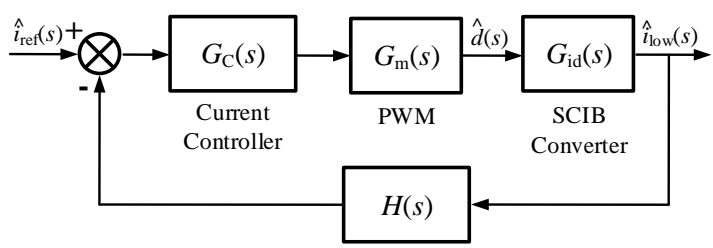

Fig.8 Current-loop control scheme for the SCIB converter.
In the closed-loop system of the SCIB converter, $G_{\mathrm{m}}(\mathrm{s})$ and $H(\mathrm{~s})$ are regarded as 1 , As to the $G_{\mathrm{c}}(\mathrm{s}), K_{\mathrm{p}}=0.001$, and $K_{\mathrm{i}}=1$. Therefore, the corresponding open-loop transfer function $G_{\text {Buck }}($ s) can be obtained as:

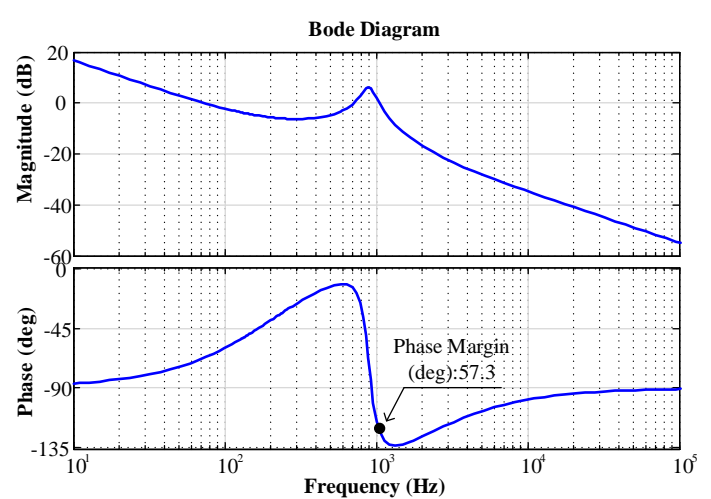

Fig.9 Bode diagram of open-loop transfer function with PI current controller in the step-down mode.

\section{III . STEADY-STATE CHARACTERISTICS ANALYSIS AND PARAMETERS COMPARISON}

\section{A. Voltage Gain Analysis}

By applying the volt-second balance principle on $L_{1} 、 L_{2}$ and $L_{3}$ in step-up and step-down modes, the relationship among voltages can be obtained as

$$
\left\{\begin{array}{l}
d_{\text {Boost }} U_{\text {low }}+\left(1-d_{\text {Boost }}\right)\left(U_{\text {low }}-U_{\text {Ch1 }}\right)=0 \\
d_{\text {Boost }} U_{\text {low }}+\left(1-d_{\text {Boost }}\right)\left(U_{\text {low }}+U_{\mathrm{C} 1}-U_{\text {Ch } 2}\right)=0 \\
d_{\text {Boost }} U_{\text {low }}+\left(1-d_{\text {Boost }}\right)\left(U_{\text {low }}+U_{\mathrm{C} 2}-U_{\text {high }}\right)=0
\end{array}\right.
$$




$$
\left\{\begin{array}{l}
d_{\text {Buck }}\left(U_{\text {low }}-U_{\mathrm{Ch} 1}\right)+\left(1-d_{\text {Buck }}\right) U_{\text {low }}=0 \\
d_{\text {Buck }}\left(U_{\text {low }}+U_{\mathrm{C} 1}-U_{\mathrm{Ch} 2}\right)+\left(1-d_{\text {Buck }}\right) U_{\text {low }}=0 \\
d_{\text {Buck }}\left(U_{\text {low }}+U_{\mathrm{C} 2}-U_{\text {high }}\right)+\left(1-d_{\text {Buck }}\right) U_{\text {low }}=0
\end{array}\right.
$$

The voltage stresses across capacitors at steady state can be written as

$$
\left\{\begin{array}{l}
U_{\mathrm{C} 1}=U_{\mathrm{Ch} 1} \\
U_{\mathrm{C} 2}=U_{\mathrm{Ch} 2}
\end{array}\right.
$$

From (12), (13) and (14), the voltage stresses across capacitors and the relationship between the output and input voltages can be obtained as

$$
\left\{\begin{array}{l}
U_{\mathrm{C} 1}=U_{\mathrm{Ch} 1}=\frac{1}{3} U_{\text {high }} \\
U_{\mathrm{C} 2}=U_{\mathrm{Ch} 2}=\frac{2}{3} U_{\text {high }} \\
U_{\text {high }}=\frac{3}{1-d_{\text {Boost }}} U_{\text {low }} \\
U_{\text {low }}=\frac{d_{\text {Buck }}}{3} U_{\text {high }}
\end{array}\right.
$$

\section{B. Voltage and Current Stresses on Power Switches}

According to the operation states of the step-up and step-down modes shown in Fig.4 and Fig.6, the equations of voltages shown in (15), and Kirchhoff's voltage law (KVL), the voltage stresses across $Q_{1}-Q_{8}$ can be obtained as

$$
\begin{aligned}
U_{\mathrm{Q} 1} & =U_{\mathrm{Q} 2}=U_{\mathrm{Q} 3}=U_{\mathrm{Q} 4}=U_{\mathrm{Q} 5} \\
& =U_{\mathrm{Q} 6}=U_{\mathrm{Q} 7}=U_{\mathrm{Q} 8}=\frac{U_{\mathrm{high}}}{3}
\end{aligned}
$$

By applying ampere-second balance principle to the capacitors, and analyzing current paths of the step-up and step-down modes over one switching period, the current stresses on $Q_{1}-Q_{3}$ in the step-up mode can be obtained as

$$
\left\{\begin{array}{l}
I_{\mathrm{Q} 1}=d_{\mathrm{Boost}} I_{\text {high }} /\left(1-d_{\text {Boost }}\right) \\
I_{\mathrm{Q} 2}=I_{\mathrm{Q} 3}=I_{\text {high }} /\left(1-d_{\text {Boost }}\right)
\end{array}\right.
$$

The current stresses on $Q_{4}-Q_{8}$ in the step-down mode can be obtained as

$$
I_{\mathrm{Q} 4}=I_{\mathrm{Q} 5}=I_{\mathrm{Q} 6}=I_{\mathrm{Q} 7}=I_{\mathrm{Q} 8}=I_{\text {high }}
$$

The average current of inductors $L_{1}-L_{3}$ can be obtained as

$$
I_{\mathrm{L} 1}=I_{\mathrm{L} 2}=I_{\mathrm{L} 3}=I_{\text {low }} / 3
$$

It can be seen from (19) that, the three-phase inductor currents are equivalent, which is one third of the low-voltage-side current $I_{\text {low }}$.

\section{Comparisons with Other Converters}

The comparison of the SCIB converter with its counterparts is shown in TABLE II. Two output capacitors are connected in series to double the output voltage in [18], however the input and output do not share a common ground, and the output capacitors must be relatively large in order to achieve the same output voltage ripple. The converter in [22] introduces multiple auxiliary inductors and capacitors for soft switching, and the voltage stresses across the power switches are high (equal to the output voltage of the HVS). The converter in [23] improves the voltage gain by charging two capacitors in parallel and discharging in series through coupled inductors. Additional absorption circuits are introduced to reduce the voltage spikes caused by leakage inductance, and the current ripple on the LVS is also large. The converter in [24] increases the voltage gain by connecting two capacitors in series on the HVS. However, the voltage stresses across power switches still remain high, and the input and output sides are not common-grounded. The converter in [25] comprises two phases. The capacitor of one of the phases charges the inductor of the other phase to achieve a high voltage gain at a cost that one of the power switches conducts both of the two-phase inductor currents. Thus it leads to a high current stress, and the voltage stress is equal to the voltage on the HVS.

TABLE II COMPARISON OF SCIB CONVERTER WITH THE COUNTERPARTS

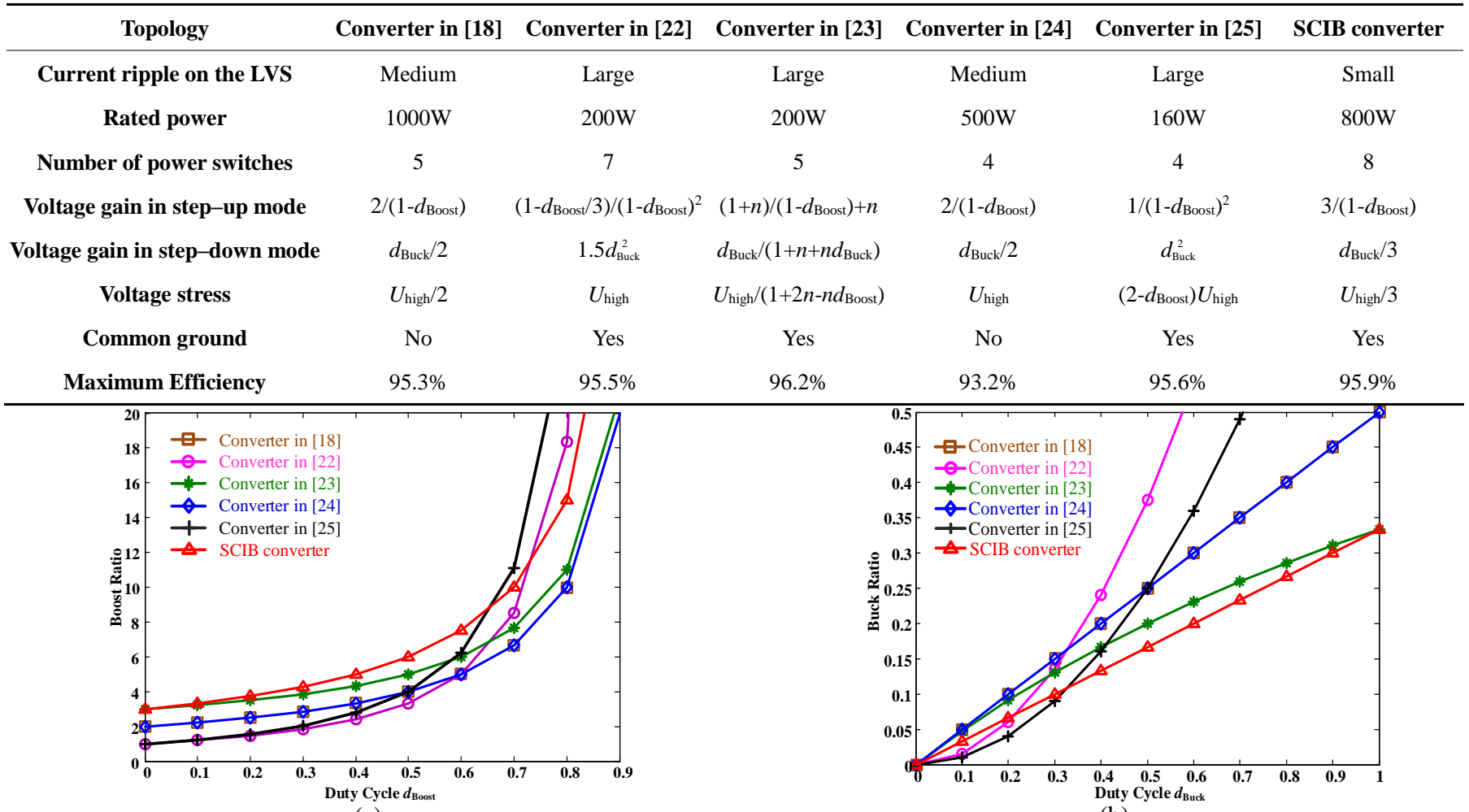

(a)

Fig.10 Comparison of voltage gain against duty cycle. (a) Step-up mode. (b) Step-down mode. 
It can be seen that the SCIB converter not only broadens the voltage gain range, but also reduces the voltage stresses across the power switches. Moreover, the three-phase interleaved structure greatly reduces the current ripple on the LVS, and the input and the output share a common ground. The efficiency of the experimental SCIB converter is competitive with its counterparts. The voltage gain against the duty cycle curves of the SCIB converter with the converters in [18],[22], [23], [24] and [25] in step-up/down mods are plotted in Fig.10, where the coupled inductor turns ratio $n$ in [23] is set as one. It is shown that the step-up voltage gain of the SCIB converter can achieve 3.75-15 within the duty cycle range of 0.2-0.8. Although the voltage gain of converters in [22] and [25] are higher than that of the SCIB converter when duty cycle $d_{\text {Boost }}>0.7$, the current ripple and voltage stress in [22] are both higher, which potentially limit its application in EVs. The voltage and current stresses in [25] are higher than that of the SCIB converter, which is not conducive to the application of the converter under the high-voltage dc bus level often required by EVs. Note that all converters apart from [22] and [23] are symmetrical in the sense that the step-up voltage gain is the inverse of step-down gain with the substitution $d_{\text {Buck }}=1-d_{\text {Boost }}$.

\section{Topology Scalability}

The SCIB converter is easy to be extended into a family with wider voltage gain ranges and higher power levels, as shown in Fig.11. The voltage gain of the extended topology operating in CCM in step-up mode can be obtained as (20):

$$
U_{\text {high }}=\frac{m}{1-d_{\text {Boost }}} U_{\text {low }}
$$

where $m$ is the number of parallel phases. Similarly, the voltage gain of the extended topology operating in CCM in step-down mode can be obtained as:

$$
U_{\text {low }}=\frac{d_{\text {Buck }}}{m} U_{\text {high }}
$$

As $m$ increases, the current ripple on the LVS becomes lower, the converter can achieve higher power levels, and the voltage stresses across all power switches are lower, i.e. $U_{\text {high }} / m$, while the current stresses keep the same relationship between the current on the HVS $I_{\text {high, }}$ which are listed in (22).

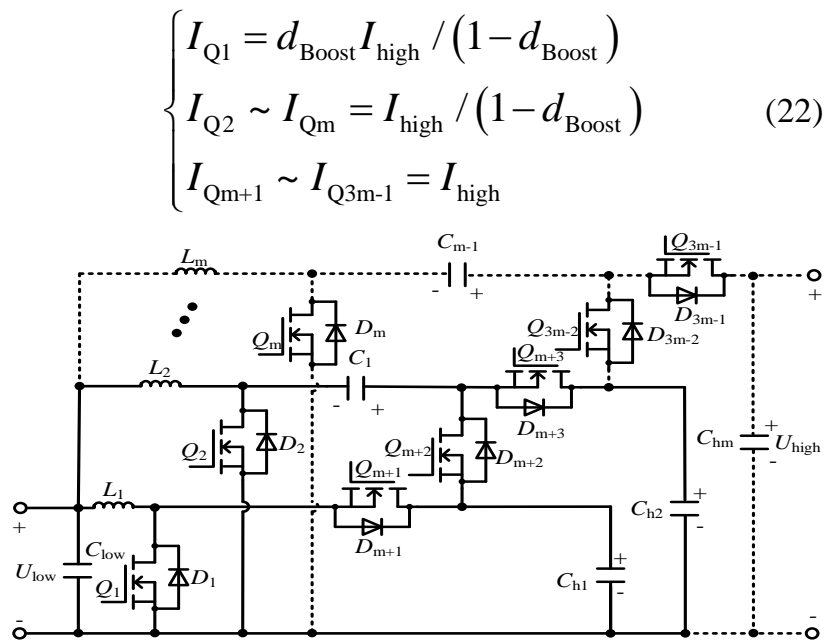

Fig.11 Extended topology family of the proposed $m$-phase converter.

\section{IV . EXPERIMENTAL RESULTS AND DISCUSSIONS}

In order to validate the effectiveness of the SCIB converter, an $800 \mathrm{~W}$ prototype has been developed as shown in Fig. 12. The experimental parameters of the converter are listed in
TABLE III. The inductances of $L_{1}-L_{3}$ and the capacitance of capacitors are selected based on (1)-(7)

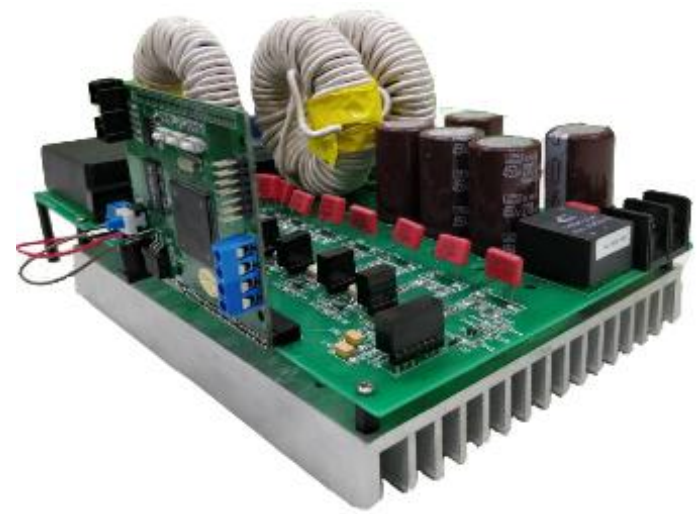

Fig.12 Prototype of the SCIB converter.

TABLE III EXPERIMENTAL PARAMETERS OF THE SCIB CONVERTER

\begin{tabular}{cc}
\hline Parameters & Values \\
\hline Voltage at low voltage side: $U_{\text {low }}$ & $30-100 \mathrm{~V}$ \\
Voltage at high voltage side: $U_{\text {high }}$ & $400 \mathrm{~V}$ \\
Rated power: $P_{\mathrm{n}}$ & $800 \mathrm{~W}$ \\
Switching frequency: $f_{\mathrm{s}}$ & $20 \mathrm{kHz}$ \\
Power MOSFETs: $Q_{1}-Q_{8}$ & IRFP4868PBF \\
Controller chip & TMS320F 28335 \\
Capacitors: $C_{1} / C_{2} / C_{\mathrm{h} 1}-C_{\mathrm{h} 3} / C_{\text {low }}$ & $270 \mu \mathrm{F} / 450 \mathrm{~V}$ \\
Inductor 1: $L_{1}$ & $352 \mu \mathrm{H} / 28 \mathrm{~A}$ \\
Inductor 2: $L_{2}$ & $350 \mu \mathrm{H} / 28 \mathrm{~A}$ \\
Inductor 3: $L_{3}$ & $346 \mu \mathrm{H} / 28 \mathrm{~A}$ \\
Designed ripple current: $\triangle I_{\mathrm{L}}$ & $2.6 \mathrm{~A}$ \\
\hline
\end{tabular}

\section{A. Wide Voltage Range}

When the SCIB converter operates in the step-up and step down modes, $U_{\text {high }}$ is held constant at $400 \mathrm{~V}$ as shown in Fig.13, while the $U_{\text {low }}$ changes from $100 \mathrm{~V}$ to $30 \mathrm{~V}$ (or vice versa) over $10 \mathrm{~s}$, simulating the discharge or charge of the

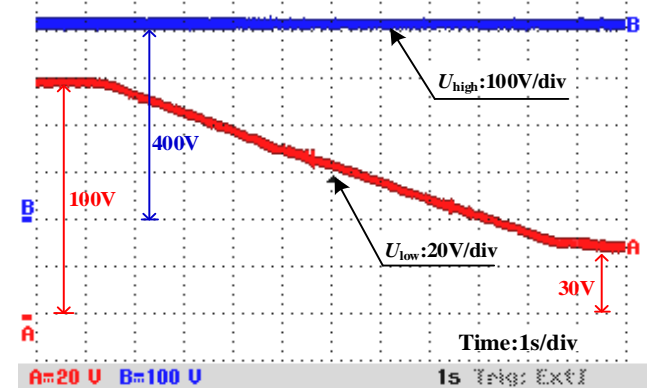

(a)

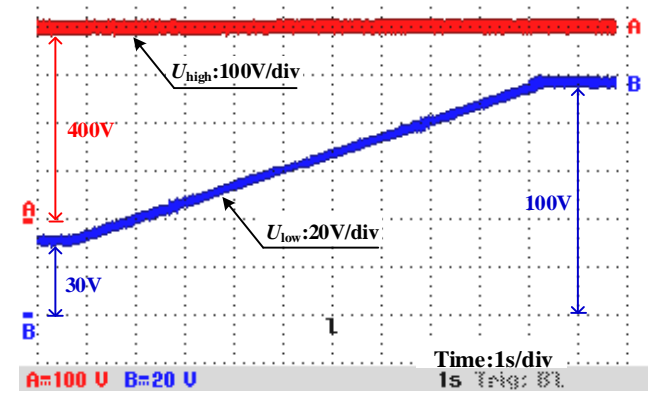

(b)

Fig.13 $U_{\text {low }}$ and $U_{\text {high }}$ waveforms. (a)Step-up mode (simulating the super capacitor banks are discharging). (b)Step-down mode (simulating the super capacitor banks are charging). 
super capacitor bank. This demonstrates the converter can achieve a wide voltage gain range from 4 to 13 in the step-up mode and from 0.075 to 0.25 in the step-down mode.

\section{B. Voltage Stress and Current Ripple}

The voltage stresses across all power switches(see Fig.14) in step-up and step-down modes are all equal to $133 \mathrm{~V}$ (1/3 of the voltage on the HVS), which is consistent with the theoretical analysis in Section III, verifying the characteristic of low voltage stress.

The input current and the currents of inductors $L_{1}-L_{3}$ in step up and step down mode are shown in Fig.15. It can be seen that the current ripples of the inductors $L_{1}, L_{2}$, and $L_{3}$ are all in the range $20-35 \%$, but the input current ripple is almost zero due to the interleaving effect, i.e., the current ripple imposed on the super capacitor is very small.

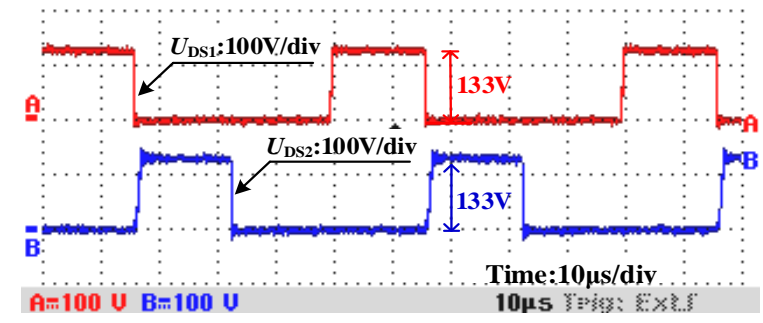

(1)-(a)

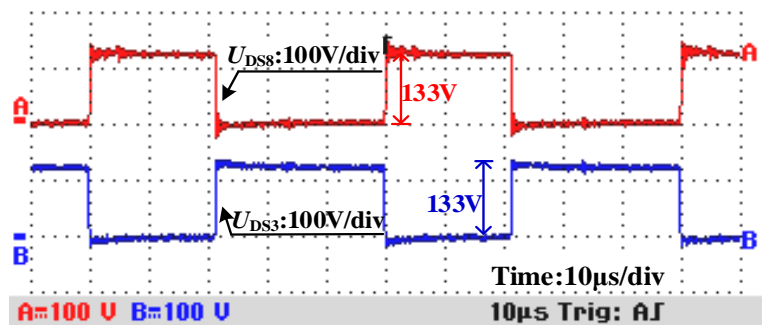

(2)-(a)

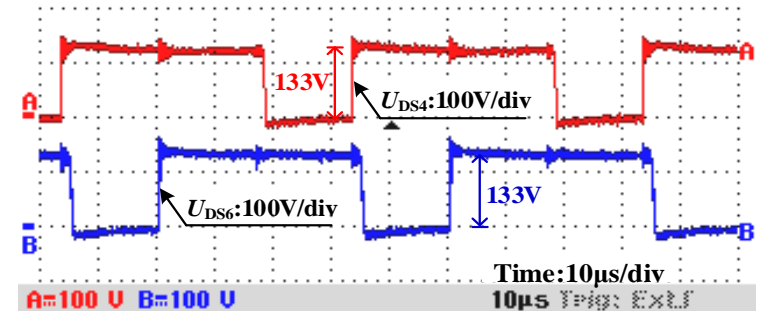

(1)-(b)

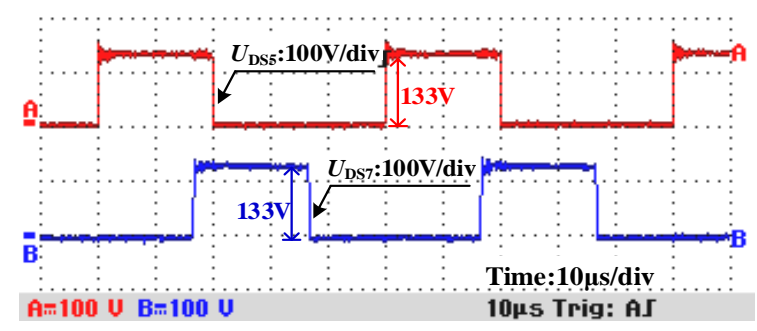

(2)-(b)

Fig.14 Voltage stresses across power switches and diodes (1)Step-up mode: (a) Voltage across power switches $Q_{1}$ and $Q_{2}$. (b) Voltage across diodes $D_{4}$ and $D_{6}$. (2)Step-down mode: (a) Voltage across power switch $Q_{8}$ and diode $D_{3}$. (b) Voltage across power switches $Q_{5}$ and $Q_{7}$.

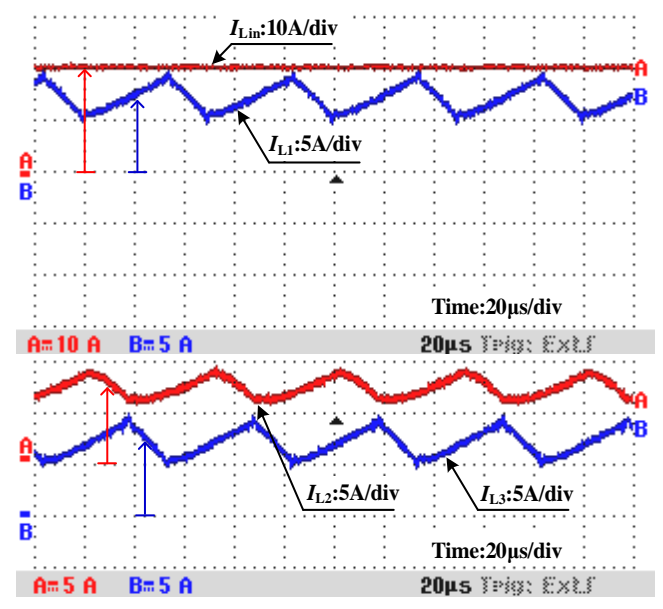

(a)

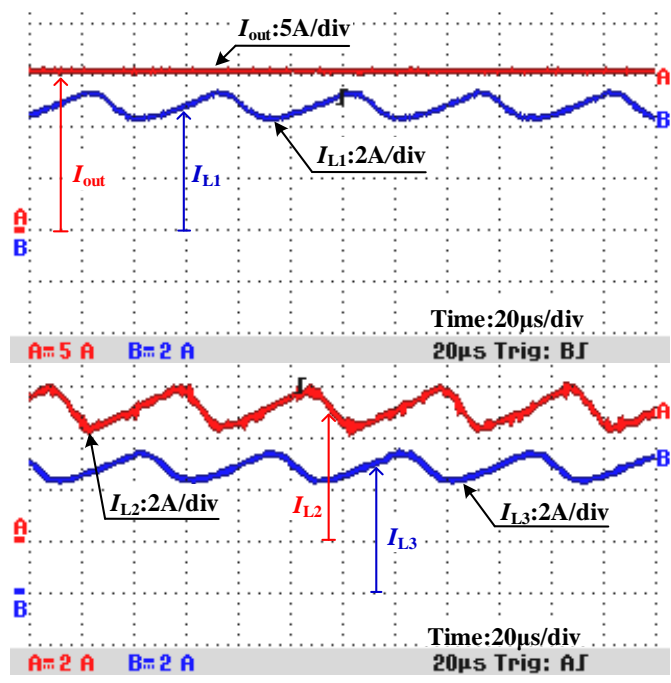

(b)

Fig.15 Inductor currents and LVS current waveforms. (a)Step-up $\operatorname{mode}\left(U_{\text {low }}=40 \mathrm{~V}, P_{\mathrm{O}}=800 \mathrm{~W}\right)$. (b)Step-down $\operatorname{mode}\left(U_{\text {low }}=50 \mathrm{~V}\right.$, $\left.P_{\mathrm{O}}=800 \mathrm{~W}\right)$.

\section{Transient Response and Bidirectional Power Flow}

The transient response of the converter is illustrated in Fig.16. It can be seen in the zoomed inset that the settling time of both transients is rapid $(60 \mu \mathrm{s}$ in step-up and $400 \mu \mathrm{s}$ in step-down mode).

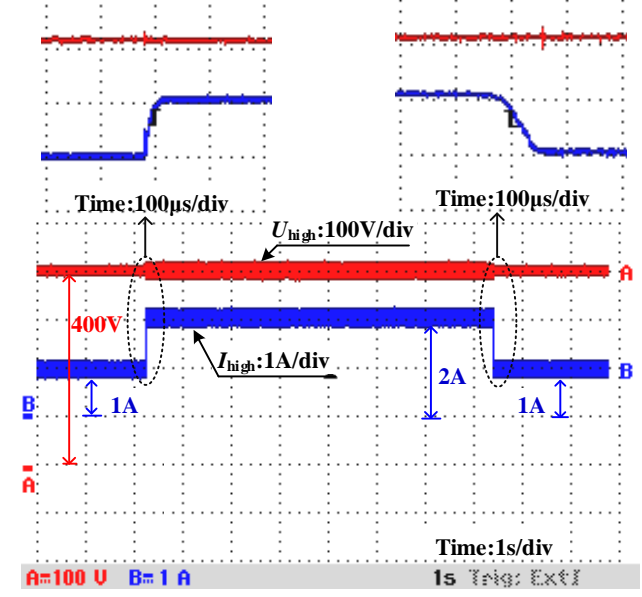

(a) 


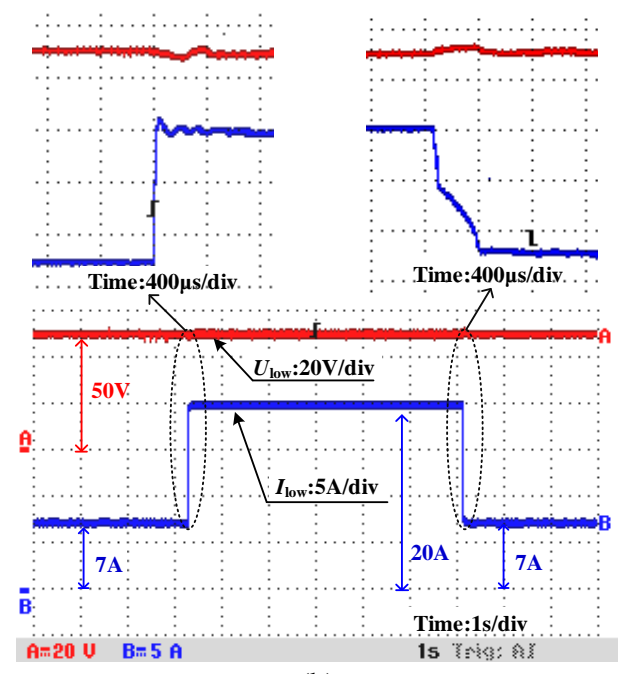

(b)

Fig.16 Output response waveforms when output power $P_{O}$ is step changed (a)Step-up mode. (b)Step-down mode.

A transition in power flow direction is shown in Fig.17 $\left(I_{\mathrm{L} 1}\right.$ is approximately one third of the total super capacitor current due to interleaving). As can be seen, the converter switches smoothly between modes.

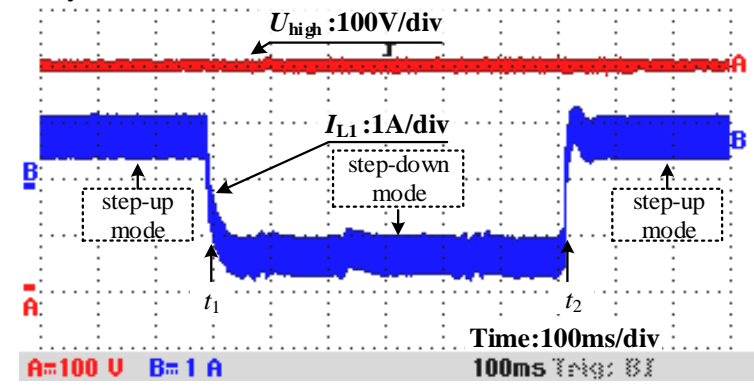

Fig.17 Experimental result of the SCIB converter in the bidirectional power flow control processes.

\section{Efficiency Analysis}

The efficiency of the experimental converter is measured by a YOKOGAWA/WT3000 power analyzer at different voltage gains and different output powers, with the results plotted in Fig.18. From Fig.18(a), the maximum and minimum efficiencies of the SCIB converter in the step-up mode are $95.8 \%$ and $89.2 \%$, respectively. From Fig.18(b), the maximum and minimum efficiencies of the SCIB converter in the step-down mode are $95.9 \%$ and $89.0 \%$, respectively. As can be seen from Fig.18, with the increase of the voltage on the LVS, i.e. lower voltage gains, the efficiency of the converter increases gradually for the same output power. With the same voltage gain, the efficiency rises gradually with the increase of the output power. If the output power continues to increase, the efficiency drops. It is observable that the peak efficiency is located approximately at the point when output power is $700 \mathrm{~W}$.

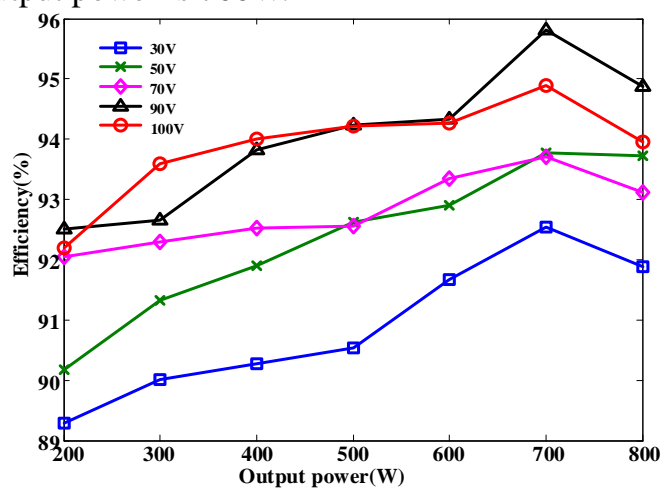

(a)

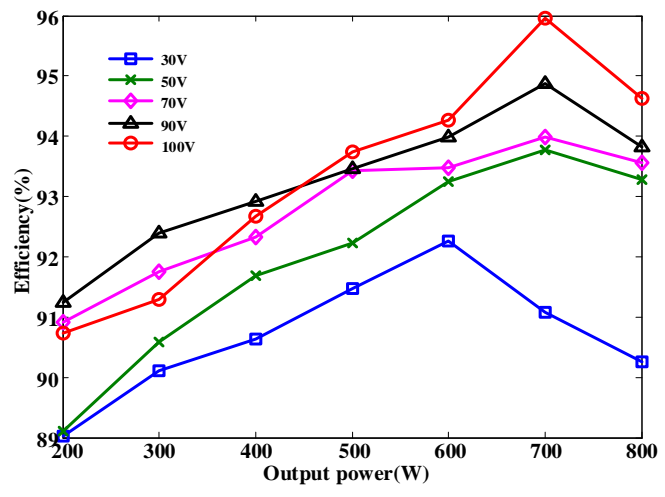

(b)

Fig. 18 Efficiency of the SCIB converter with $U_{\text {high }}=400 \mathrm{~V}, U_{\text {low }}=$ 30-100V and $P_{\mathrm{O}}=200-800 \mathrm{~W}$. (a)Step-up mode. (b)Step-down mode.

The experimental power loss distributions when $U_{\text {high }}=400 \mathrm{~V}, U_{\text {low }}=50 \mathrm{~V}$ and $P_{\mathrm{o}}=800 \mathrm{~W}$ are calculated, which are shown in Fig.19. When the SCIB converter operates in the step-up mode, the total losses of the converter are 53.6W. As can be seen in Fig.19(a), the major losses come from the switching losses of power switches $Q_{1}-Q_{3}$ and the losses of diodes $D_{4}-D_{8}$. Similarly, when the SCIB converter operates in the step-down mode(see in Fig.19(b)), the major losses are from the switching losses of power switches $Q_{4}-Q_{8}$ and the losses of diodes $D_{1}-D_{3}$.

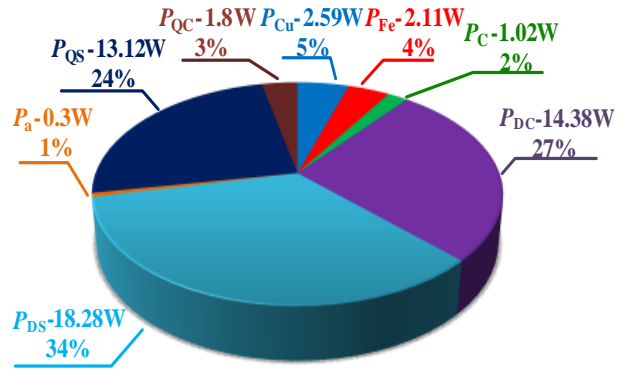

(a)

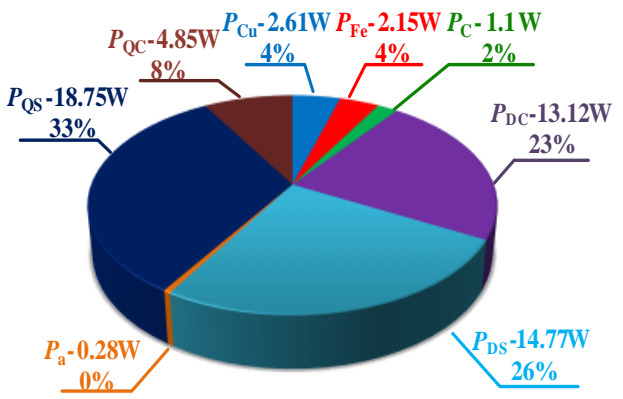

(b)

Fig.19 Calculated power loss distributions for the converter when $U_{\text {low }}=50 \mathrm{~V}, \quad U_{\text {high }}=400 \mathrm{~V}$ and $P_{\mathrm{O}}=800 \mathrm{~W}$. (a) Step-up mode. (b) Step-down mode. Labels- $P_{\mathrm{QS}}$ : MOSFET switching losses, $P_{\mathrm{QC}}$ : MOSFET conduction losses, $P_{\mathrm{DS}}$ : diode switching losses, $P_{\mathrm{DC}}$ : diode conduction losses, $P_{\mathrm{Cu}}$ : inductor copper losses, $P_{\mathrm{Fe}}$ : inductor iron losses, $P$ a: other losses.

\section{CONCLUSION}

A switched-capacitor three-phase interleaved bidirectional dc-dc converter, named the SCIB converter, has been proposed in this paper. The converter benefits from a wide voltage gain range in step-up and step-down modes and an absolute common ground between input and output. In addition, the current ripple on the LVS is very low and the voltage stresses across all power switches are just one-third of the voltage on the HVS. The converter has good topology scalability and extended topologies of an $m$-phase interleaved structure can be easily obtained. Therefore, it is a good candidate for the power interface between super capacitor banks, which have a naturally widely varying terminal 
voltage, and the constant high voltage dc bus in hybrid energy sources EVs.

\section{REFERENCES}

[1] J. Y. Yong, V. K. Ramachandaramurthy, K. M. Tan, N. Mithulananthan, "A review on the state-of-the-art technologies of electric vehicle its impacts and prospects", Renew. Sust. Energ. Rev., vol. 49, no. 1, pp. 365-385, 2015.

[2] B. Bilgin, P. Magne, P. Malysz, Y. Yang, V. Pantelic, M. Preindl, A. Korobkine, W. Jiang, M. Lawford, A. Emadi, "Making the case for electrified transportation", IEEE Trans. Transport. Electrific., vol. 1, no. 1 , pp. 4-17, 2015.

[3] L. Jian, H. Xue, G. Xu, X. Zhu, D. Zhao and Z. Y. Shao, "Regulated charging of plug-in hybrid electric vehicles for minimizing load variance in household smart microgrid," IEEE Trans. Ind. Electron., vol. 60 , no. 8, pp. 3218-3226, Aug. 2013.

[4] Z. Amjadi and S. S. Williamson, "Power-electronics-based solutions for Plug-in hybrid electric vehicle energy storage and management systems," IEEE Trans. Ind. Electron., vol. 57, no. 2, pp. 608-616, Feb. 2010.

[5] A. Affanni, A. Bellini, G. Franceschini, P. Guglielmi and C. Tassoni, "Battery choice and management for new-generation electric vehicles," IEEE Trans. Ind. Electron., vol. 52, no. 5, pp. 1343-1349, Oct. 2005 .

[6] G. G. Oggier, G. O. Garcĺa and A. R. Oliva, "Switching Control Strategy to Minimize Dual Active Bridge Converter Losses," IEEE Trans. Power Electron., vol. 24, no. 7, pp. 1826-1838, July 2009.

[7] J. Qi and D. D. Lu, "A preventive approach for solving battery imbalance issue by using a bidirectional multiple-input Cuk converter working in DCVM," IEEE Trans. Ind. Electron., vol. 64, no. 10, pp. 7780-7789, Oct. 2017.

[8] A. Shrivastava, B. Singh and S. Pal, "A novel wall-switched step-dimming concept in LED lighting systems using PFC Zeta converter," IEEE Trans. Ind. Electron., vol. 62, no. 10, pp. 6272-6283, Oct. 2015.

[9] P. J. Grbovic, P. Delarue, P. Le Moigne and P. Bartholomeus, "A bidirectional three-level DC-DC converter for the ultracapacitor applications," IEEE Trans. Ind. Electron., vol. 57, no. 10, pp. 3415-3430, Oct. 2010.

[10] V. Monteiro, J. C. Ferreira, A. A. Nogueiras Meléndez and J. L. Afonso, "Model predictive control applied to an improved five-level bidirectional converter," IEEE Trans. Ind. Electron., vol. 63, no. 9, pp. 5879-5890, Sept. 2016.

[11] H. Jou, J. Huang, J. Wu and K. Wu, "Novel Isolated Multilevel DC DC Power Converter," IEEE Trans. Power Electron., vol. 31, no. 4 , pp. 2690-2694, April 2016.

[12] T. Nouri, N. Vosoughi, S. H. Hosseini, E. Babaei and M. Sabahi, "An Interleaved High Step-Up Converter With Coupled Inductor and Built-In Transformer Voltage Multiplier Cell Techniques," IEEE Trans. Ind. Electron., vol. 66, no. 3, pp. 1894-1905, March 2019.

[13] J. Ai and M. Lin, "Ultralarge Gain Step-Up Coupled-Inductor DC DC Converter With an Asymmetric Voltage Multiplier Network for a Sustainable Energy System," IEEE Trans. Power Electron., vol. 32, no. 9, pp. 6896-6903, Sept. 2017

[14] J. Lee and B. Kwon, "DC-DC Converter using a multiple-coupled inductor for low output voltages," IEEE Trans. Ind. Electron., vol. 54, no. 1, pp. 467-478, Feb. 2007

[15] Y. Tang, D. Fu, T. Wang and Z. Xu, "Hybrid switched-inductor converters for high step-up conversion," IEEE Trans. Ind. Electron., vol. 62, no. 3, pp. 1480-1490, March 2015.

[16] M. A. Salvador, T. B. Lazzarin and R. F. Coelho, "High step-up DC-DC converter with active switched-inductor and passive switched-capacitor networks," IEEE Trans. Ind. Electron., vol. 65, no. 7, pp. 5644-5654, July 2018.

[17] S. Xiong and S. Tan, "Cascaded high-voltage-gain bidirectional switched-capacitor DC-DC converters for distributed energy resources applications," IEEE Trans. Power Electron., vol. 32, no. 2, pp. 1220-1231, Feb. 2017.

[18] Y. Zhang, Y. Gao, J. Li and M. Sumner, "Interleaved switched-capacitor bidirectional DC-DC converter with wide voltage-gain range for energy storage systems," IEEE Trans. Power Electron., vol. 33, no. 5, pp. 3852-3869, May 2018.

[19] L. Yang and T. Liang, "Analysis and implementation of a novel bidirectional DC-DC converter," IEEE Trans. Ind. Electron., vol. 59, no. 1, pp. 422-434, Jan. 2012.

[20] M. M. Chen and K. W. E. Cheng, "A new bidirectional DC-DC converter with a high step-up/down conversion ratio for renewable energy applications," Proc. Int. Symp. Elect. Eng., Hong Kong, 2016, pp. 1-6.

[21] Cornea, G. Andreescu, N. Muntean and D. Hulea, "Bidirectional power flow control in a DC microgrid through a switched-capacitor cell hybrid DC-DC converter," IEEE Trans. Ind. Electron., vol. 64, no. 4, pp. 3012-3022, April 2017

[22] R. H. Ashique and Z. Salam, "A high-gain, high-efficiency nonisolated bidirectional DC-DC converter with sustained ZVS Operation," IEEE Trans. Ind. Electron., vol. 65, no. 10, pp. 7829-7840, Oct. 2018.

[23] Y. Hsieh, J. Chen, L. Yang, C. Wu and W. Liu, "High-conversion-ratio bidirectional DC-DC converter with coupled inductor," IEEE Trans. Ind. Electron., vol. 61, no. 1, pp. 210-222, Jan. 2014.

[24] S. Liao, J. Teng and S. Chen, "Bidirectional DC-DC converter with high step-down and step-up voltage conversion ratio," IEEE Annual Southern Power Electron. Conf. (SPEC), Auckland, 2016, pp. 1-6.

[25] H. Ardi, A. Ajami, F. Kardan and S. N. Avilagh, "Analysis and implementation of a nonisolated bidirectional DC-DC converter with high voltage gain," IEEE Trans. Ind. Electron., vol. 63, no. 8, pp. 4878-4888, Aug. 2016

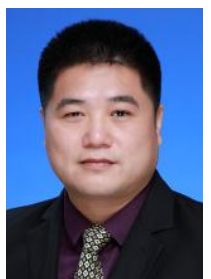

Yun Zhang (M'13-SM'18) was born in Jiangsu, China, in 1980. He received the B.S. and M.S. degrees in electrical engineering from the Harbin University of Science and Technology, Harbin, China, in 2003 and 2006, respectively, and the Ph.D. degree in electrical engineering from the Harbin Institute of Technology, Harbin, China, in 2010.

In 2010, he joined the Tianjin University, Tianjin, China, as a Lecturer in the School of Electrical and Information Engineering, where he is currently a Professor. From December 2016 to December 2017, he was an Academic Visitor with the Power Electronics, Machines and Control (PEMC) Group at the University of Nottingham, Nottingham, U.K. His current research interests include topologies, modulation, and control strategies of power converters for electric vehicles and microgrids.

Dr. Zhang is an Associate Editor of the JOURNAL OF POWER ELECTRONICS

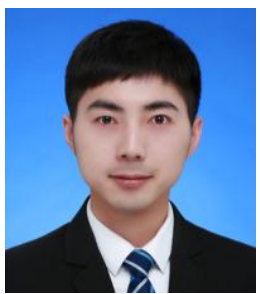

Wei Zhang was born in Anhui, China. He received the B.S. degree in electrical engineering from Fuzhou University, Fuzhou, China, in 2017. He is currently working toward the M.S. degree in electrical engineering from Tianjin University, Tianjin, China in 2017.

His current research interests include dc-dc converters and energy management.

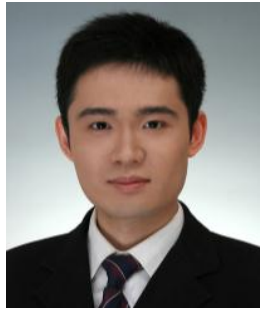

Fei Gao (M'19) received his M.Sc. degree in Electrical Engineering from Shanghai Jiao Tong University, Shanghai, China, in 2010. He received his Ph.D. degree in Electrical Engineering for his work on control and stability analysis of more electric aircraft electrical power systems from the PEMC Research Group, University of Nottingham, Nottingham, UK, in 2016.

From Mar. 2010 to Sep. 2012, he has worked in Jiangsu Electric Power Research Institute, Nanjing, State Grid Corporation of China. Since Nov. 2016, he has joined Energy and Power Group, University of Oxford, UK as a postdoctoral researcher. His current research interests include modelling, control, power management and stability of hybrid ac/dc microgrids and more electric transportation systems. Dr. Gao won the European Union Clean Sky Best PhD Award in 2017.

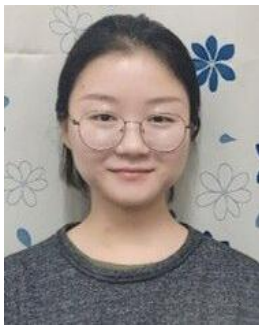

Shenghan Gao was born in Anhui, China. She received her B.S. degree in North China University of Technology, Beijing, China, in 2018 She started pursing her M.S. degree in Electrical Engineering from the Tianjin University, Tianjin, China, in 2018.

Her current research interests include DC-DC converters, and energy management of electric vehicles.

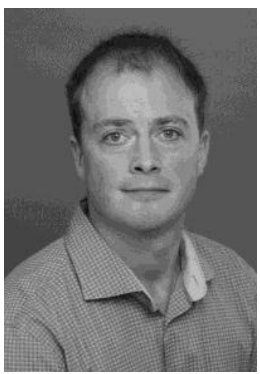

Daniel J. Rogers (M'09) received the M.Eng. and $\mathrm{Ph} . \mathrm{D}$. degrees in electrical and electronic engineering from Imperial College London, London, U.K., in 2007 and 2011 respectively. He is an Associate Professor in the Department of Engineering Science at the University of Oxford, UK. He conducts research in collaboration with industry and is an investigator on UK EPSRC research projects in the areas of power electronics, grid-scale energy storage, microgrids and HVDC transmission. Dan's research interests include the 
use of medium- and large-scale power electronic systems to create flexible electrical networks that take advantage of a diverse range of generation and storage technologies. 